\title{
Does birth weight affect nutritional status at the end of first year of life?
}

\author{
Maria Eugênia Farias Almeida Motta, ${ }^{1}$ Gisélia Alves Pontes da Silva, ${ }^{2}$ \\ Ozanil Cursino Araújo, ${ }^{3}$ Pedro Israel Lira, ${ }^{4}$ Marília de Carvalho Lima ${ }^{5}$
}

\begin{abstract}
Objective: To evaluate the association between low birth weight and nutritional status at the end of the first year of life.

Methods: This was a nested case-control study within a cohort. The study was carried out at maternity hospitals in four cities in the Zona da Mata Meridional in Pernambuco state, Brazil. Newborn infants were recruited during the first 24 hours of life. Their weights were measured at birth and at the end of the first year of life. Household visits were made twice weekly during the first year of life to collect data on breastfeeding and occurrence of diarrhea. In the case-control study, each case (child at nutritional risk) was a child with weight-for-age index < the 10th percentile $(n=117)$ and each control was a child with weight-for-age index $\geq$ the 10th percentile $(n=411)$. Hierarchical logistic regression analysis was used to investigate risk factors for nutritional status at 12 months.

Results: Low birth weight and living in a household with no latrine were significantly associated with nutritional risk at the end of the first year of life. Children born weighing $1,500 \mathrm{~g}$ to $2,499 \mathrm{~g}$ had 29 times ( $95 \% \mathrm{CI}=9.77-87.49$ ) the chance of being at nutritional risk at 12 months of life than those whose birth weights had been $>3,500 \mathrm{~g}$ $(p<0.001)$. Children living in households without a flush toilet had three times $(95 \% \mathrm{CI}=1.54-6.22)$ the chance of nutritional risk at 12 months of life in relation to those that had a latrine with a septic tank at home $(p=0.01)$.

Conclusion: Low birth weight is an important risk factor of nutritional risk at the end of the first year of life. It is important to adopt strategies for its reduction and prevention.
\end{abstract}

J Pediatr (Rio J). 2005;81(5):377-82: Nutrition assessment, low birth weight infant, weight age, case-control study.

\section{Introduction}

Birth weight measured during the first hour after birth reflects the nutritional status of both the newborn infant and the recently delivered mother and is considered an appropriate indicator of individual health. Birth weight has an influence on the child's growth and development and,

1. PhD. Researcher, Universidade Federal de Pernambuco (UFPE), Recife, PE, Brazil.

2. PhD. Professor, Mother and Child Department, UFPE, Recife, PE, Brazil.

3. MSc. Physician, Instituto Materno Infantil de Pernambuco (IMIP), Recife, PE, Brazil.

4. PhD. Professor, Department of Nutrition, UFPE, Recife, PE, Brazil.

5. PhD. Professor. Coordinator of the MSc Program on Child and Adolescent Health, Mother and Child Department, UFPE, Recife, PE, Brazil.

Manuscript received Dec 02 2004, accepted for publication Jun 032005.

Suggested citation: Motta ME, da Silva GA, Araújo OC, Lira PI, Lima MC. Does birth weight affect nutritional status at the end of first year of life? $\mathrm{J}$ Pediatr (Rio J). 2005;81:377-82. over the long term, has repercussions for the health of the adult. ${ }^{1}$ Low birth weight (LBW) is a risk factor linked with both infant mortality and morbidity and is used to investigate the conditions for survival and the quality of life of individuals. ${ }^{2}$

The World Health Organization (WHO) defines newborn infants weighing $<2.500 \mathrm{~g}$ as LBW, irrespective of gestational age. ${ }^{3}$ In developed countries, LBW is linked to prematurity in almost all cases; in developing countries, however, its principal cause is intrauterine growth restriction. ${ }^{4}$

Low birth weight has been identified as an important determining factor for malnutrition. Olinto et al. observed that LBW children had a nine times greater chance of presenting a stature/age (S/A) deficit by the end of their second year of life, when compared with those born at adequate weight. ${ }^{5}$ Gigante et al. found a higher percentage of children with deficits in weight/age (W/A) and S/A indices at the end of their first year of life among those who had 
been born at LBW. ${ }^{6}$ Notwithstanding, other variables, such as unfavorable socioeconomic conditions, early weaning and diarrhea also contribute to nutritional deficits, thereby interfering with interpretation of the association of birth weight with nutritional status in the form of confounding variables. 7

Childhood malnutrition, manifest by severely compromised linear growth and/or extreme emaciation, is one of the most serious problems in developing societies. The proportion of malnourished children has been falling over the last 20 years, principally in counties in the Americas. ${ }^{8}$ In Brazil, the recent tendency is towards a reduction in the prevalence of malnutrition in all social strata, although it still occurs in a heterogeneous manner with levels that remain elevated in the North and Northeast regions. ${ }^{9}$

Childhood malnutrition is one of the most relevant problems in public health, particularly so in less developed regions, as is the case in the rural areas of the Brazilian Northeast. It is the result of insufficient nutrition allied with avoidable diseases and primarily affects the low-income population, who have poverty as their condition and social and economic underdevelopment as causative historical process. 10

Based on the assumption that, depending upon regional characteristics, the factors associated with nutritional abnormalities may differ, the objective of this study was to analyze the association between LBW and nutritional status after one year of life in children bone in the Zona da Mata Meridional of Pernambuco state and to identify possible confounding factors by logistic regression analysis.

\section{Methods}

This was a nested case-control study within a cohort, undertaken in four towns (Água Preta, Catende, Joaquim Nabuco, Palmares) in the Zona da Mata Meridional in Pernambuco state; located around $120 \mathrm{~km}$ from the state capital, Recife. Marques et al. have described the socioeconomic characteristics of these towns. ${ }^{11}$ The regional economy is based on the cultivation and processing of sugar cane, with the majority of the economically active population working in this sector. The population for the cohort study comprised newborn infants recruited during their first 24 hours of life at the six maternity units that exist in the study region. Inclusion criteria were authorization from parents for participation with written free and informed consent and permanent residence in the urban area of one of the towns. Exclusion criteria were multiple births, newborn infants with clinical signs of congenital, infections, genetic syndromes or malformations. A form was filled out for the parents of each child by previously trained research assistants in order to obtain the socioeconomic characteristics of the study population. The weight of the newborn infants was measured using a portable digital balance (model 725, Soenhe, Hamburg, Germany), with a $15 \mathrm{~kg}$ capacity and sensitivity of $10 \mathrm{~g}$. Follow-up home visits were made twice weekly for the first year of life by a team of 13 trained health visitors in order to obtain information on maternal breastfeeding and morbidity from diarrhea. The visitor filled out a form with information from parents or guardians, recording information on morbidity due to diarrhea and type of feeding. For this study predominant breastfeeding was defined as when the infant was given water or water-based drinks such as fruit juices or teas in addition to breastmilk. ${ }^{12}$ Diarrhea was defined as $\geq$ three wet evacuations in 24 hours or a single evacuation containing blood during the period between the most recent visit and the preceding one. For breastfed children the definition was based on what the mother considered to be diarrhea. Diarrhea episodes were defined as starting during the first 24 hours in which the definition of diarrhea was fulfilled and ending on the last day of diarrhea. Diarrhea episodes were separated by a minimum of 2 days on which the definition of diarrhea was not met. At 12 months of age, the weight of those children that remained in the cohort was measured during a home visit, with children unclothed and using a portable balance with a $25 \mathrm{~kg}$ capacity (model Mp25, CMS Ltd., London, United Kingdom). The comparison groups for the case-control study were formed by defining a case (nutritional risk) as a child with a W/A index < percentile 10 and a control as a child with W/A index $\geq$ percentile 10 , according to the reference curve for the American population provided by the National Center for Health Statistics (NCHS). ${ }^{13}$

The sample size calculation for the case-control study was performed with Epi-Info 6.04. The variable of greatest interest was employed, i.e. birth weight, in order to confirm whether the number of children followed until 1 year of life would be enough to carry out the case-control study. Defining alpha error as $5 \%$, study power as $90 \%$, a proportion of one case to four controls, a frequency of $67.5 \%$ of LBW infants among the cases and of $35.1 \%$ among the controls, the minimum sample size for the study was 33 cases and 132 controls. Since 528 children were followed to the end of the cohort study, all of these were included in the casecontrol study to afford greater consistency to the logistic regression analysis.

The exposures analyzed (independent variables) were living conditions (type of sanitation, water source), presence or absence of a refrigerator in the residence, birth weight, duration of predominant breastfeeding and diarrhea episodes. The outcome (dependent variable) was nutritional status at the end of the first year of life, defined by the W/A index and taking the 10 th percentile as the cutoff point.

Data was stored using Epi-Info, version 6.04 (CDC, Atlanta) and was double input for validation. The statistical analysis was performed using the Statistical Package for the Social Sciences, version 10.0 for Windows (SPSS Inc., Chicago, IL, USA). Initially a bivariate analysis was performed with nutritional status at the end of the first year of life and each of its potential determinants - presence or absence of a refrigerator in the residence, water source, type of sanitation, birth weight, duration of predominant breastfeeding and number of episodes of diarrhea - which had been selected for study because of a possible relationship with the dependent variable or because they were related to the occurrence of protein-energy malnutrition (PEM) at the 
end of the first year of life. ${ }^{7}$ The base category for calculating adjusted and unadjusted odds ratio estimates was defined as that with the least risk of the appearance of nutritional risk. For statistical association acceptance, the odds ratio $95 \%$ confidence interval and a significance level of $5 \%$ were used.

Assuming that several different factors may cause PEM, a multivariate analysis was performed by logistic regression in order to control for possible confounding factors. The analytical procedure adopted was the hierarchical method by which variables are entered in a sequence that has been previously established by the researcher, according to a model that describes logical or theoretical relationships between risk factors for the study variable. ${ }^{5}$ Thus, five regression models were constructed, according to relationships that have been described between risk factors for PEM. ${ }^{14}$ In the first model, presence of a refrigerator was given the top level, representing socioeconomic variables that could directly or indirectly determine all of the study variables. The environmental variables (water source and type of sanitation) were then added to create the second model. The third model was constructed with the addition of birth weight, the fourth by adding duration of predominant breastfeeding and the fifth by including the number of episodes of diarrhea. Those variables that remained significant to $20 \%$ were maintained and used in the next, adjusted model and once a variable had been selected at a given level it was kept in subsequent models even if it lost significance as variables were added in at lower levels in the hierarchy.

The research project was approved by the Committee for Ethics in Research at the Health Sciences Center of the Universidade Federal de Pernambuco.

\section{Results}

The cohort study followed-up 528 children until one year of age. One hundred and seventeen children (22.2\%) at nutritional risk and 411 children (77.8\%) with adequate weight were included in the case-control study.

Factors that explained nutritional risk at the end of the first year of life were absence of a flush toilet at home and birth weight.

Those children living in homes without sanitation had a three times greater chance $(\mathrm{OR}=3.09 ; 95 \% \mathrm{CI}=1.54$ 6.22 ) of being at nutritional risk at the end of their first year of life when compared with those who had a flush toilet at home $(p \leq 0.01)$ (Table 1$)$.

Concerning birth weight, the chance of presenting nutritional risk at 12 months of age was 29 times greater for children who were born weighing $1,500 \mathrm{~g}$ to $2,499 \mathrm{~g}$ (OR = 29.24; 95\% CI = 9.77-87.49; $p<0.001)$, seven times greater for those weighing $2,500 \mathrm{~g}$ to $2,999 \mathrm{~g}$ (OR $=6.98$; $95 \% \mathrm{CI}=2.66-18.36 ; \mathrm{p}<0.001)$ and three times greater for those born weighing $3,000 \mathrm{~g}$ to $3,499 \mathrm{~g}(\mathrm{OR}=3.54 ; 95 \%$ $\mathrm{CI}=1.32-9.47 ; \mathrm{p}<0.05)$, when compared with children whose birth weights had been $\geq 3,500 \mathrm{~g}$ (Table 1 ).
The variables water source and episodes of diarrhea, which had been associated with nutritional risk at the end of the first year of life after bivariate analysis $(p<0.05)$ lost their statistical significance in the multivariate regression analysis (Table 1 ).

\section{Discussion}

Understanding the process of physical growth and the factors that determine it during the first years of life remains an area of active investigation in child health. ${ }^{13}$ This, more than anything, is the result of accumulated knowledge about the long-term repercussions of failure to thrive during childhood, such as physical and cognitive deficits and morbidity and mortality. ${ }^{15-17}$

Physical growth is internationally recognized as an indicator of nutritional status, since adequate nutrition permits normal growth. ${ }^{18,19}$ Therefore, anthropometric evaluation facilitates early identification of and intervention in emerging nutritional and health problems, minimizing their consequences. ${ }^{17} \mathrm{~A}$ combination of anthropometric measurements (weight and stature) generates the indices that allow growth to be interpreted. 4,18 Anthropometric indices provide an indication of nutritional risk, the term of preference since malnutrition presages an underlying pathological process, which is impossible to confirm on the basis of anthropometrics alone. ${ }^{14,18}$ The W/A index transforms body mass with respect to chronological age and, indirectly, expresses the S/A index, which represents linear growth specifically. ${ }^{14}$

Differences in childhood patterns of physical growth can be the result of a number of different factors: prenatal variables that affect size and proportionality at birth, including the effects of intrauterine growth restriction on the programming of postnatal growth, and postnatal variables, such as morbidity and nutrition. ${ }^{15,17}$ It is important to identify which of these factors has the most influence on a given population in order that adequate preventative measures can be adopted in each area thus optimizing public health resources.

In the present study it has been observed that LBW was a contributing factor to nutritional risk at the end of the first year of life. In this sample, LBW and inadequate weight reflect intrauterine growth restriction, the principal cause of which is maternal malnutrition allied with poor living conditions and prenatal care. ${ }^{20}$ Similar results have been reported in the past and the association remained significant after controlling for confounding variables. ${ }^{2,7}$ In areas with high prevalence rates of malnutrition it has also been observed that LBW has an important function in reduced physical growth, lasting for years, and that postnatal factors have only a partial influence. ${ }^{21}$ According to Arifeen et al., children with normal birth weights gain an average of $73 \mathrm{~g}$ more than LBW children during their first three months of life, which possibly makes them more vulnerable to postnatal factors which may act on them after this age. ${ }^{21}$ It was precisely from 3 to 12 months that the weight and stature of children in rural South Africa deviated significantly below 
Table 1 - Logistic regression model of risk factors of nutritional risk in children in the Zona da Mata Meridional in Pernambuco state, 1997-1998

\begin{tabular}{|c|c|c|c|c|}
\hline \multirow[t]{2}{*}{ Variables } & \multicolumn{2}{|c|}{ Weight/age index } & \multirow{2}{*}{$\begin{array}{l}\text { unadjusted OR } \\
(95 \% \text { IC) }\end{array}$} & \multirow{2}{*}{$\begin{array}{l}\text { adjusted OR } \\
(95 \% \text { IC) }\end{array}$} \\
\hline & $<\mathbf{P}_{10}$ & $\geq \mathbf{P}_{10}$ & & \\
\hline \multicolumn{5}{|l|}{ Refrigerator * } \\
\hline Yes & 43 & 243 & 1 & 1 \\
\hline No & 74 & 168 & $2.49(1.63-3.8)^{\dagger}$ & $1.6(0.94-2.62)^{\ddagger}$ \\
\hline \multicolumn{5}{|l|}{ Water source $\S$} \\
\hline Piped & 90 & 362 & 10 & \\
\hline Nonpiped & 27 & 49 & $2.22(1.31-3.74)^{i}$ & ๆ \\
\hline \multicolumn{5}{|l|}{ Type of toilet $\S$} \\
\hline With flushing device & 50 & 262 & 1 & 1 \\
\hline Without flushing device & 41 & 117 & $1.84(1.15-2.93) !$ & $1.39(0.81-2.37)^{\ddagger}$ \\
\hline No toilet & 26 & 32 & $4.26(2.34-7.75)^{\dagger}$ & $3.09(1.54-6.22)$ \\
\hline \multicolumn{5}{|l|}{ Birth weight $(\mathbf{g}) * *$} \\
\hline$\geq 3,500$ & 5 & 96 & 1 & 1 \\
\hline $3,000-3,499$ & 33 & 171 & $3.7(1.4-9.78) !$ & $3.54(1.32-9.47)^{+\dagger}$ \\
\hline $2,500-2,999$ & 50 & 127 & $7.55(2.9-19.63)^{\dagger}$ & $6.98(2.66-18.36)^{+}$ \\
\hline $1,500-2,499$ & 29 & 17 & $32.7(11.11-96.25)^{\dagger}$ & $29.24(9.77-87.49)^{\dagger}$ \\
\hline \multicolumn{5}{|l|}{$\begin{array}{l}\text { Duration of predominant } \\
\text { breastfeeding (months) }\end{array}$} \\
\hline$\geq 7$ & 30 & 127 & 1 & \\
\hline$\overline{4-6}$ & 20 & 55 & $1.54(0.81-2.94)^{\ddagger}$ & ๆ \\
\hline $2-3$ & 54 & 180 & $1.27(0.77-2.1) \neq$ & ๆ \\
\hline 1 & 13 & 49 & $1.12(0.54-2.33)^{\neq}$ & १ \\
\hline \multicolumn{5}{|l|}{ Episodes of diarrhea $\S \S$} \\
\hline $0-1$ & 28 & 148 & 1 & 1 \\
\hline$\geq 2$ & 89 & 263 & $1.79(1.12-2.86)^{+\dagger}$ & $1.48(0.89-2.47)^{\ddagger}$ \\
\hline
\end{tabular}

Model variables: ${ }^{*}$ model $1 ; \S$ model $2 ;{ }^{* \star}$ model 3 ; 㧊 model $4 ;$ §§ model 5 .

Significance level: ${ }^{\dagger} p<0.001 ; \ddagger p>0.05 ; \quad p \leq 0.01 ;{ }^{\dagger} p<0.05$.

$\uparrow$ variables without adjusted OR because they were not kept in the model adjustement $(p>0.20)$.

the NCHS reference curves, probably coinciding with the introduction of inappropriate complementary foods with a concurrent increase in the incidence of diarrhea. ${ }^{17}$ However, both LBW children and those born at normal weight are potentially exposed to these factors. What differentiates the LBW children is that, irrespective of excellent catch up growth during the first three months of life, they remain below the children with adequate birth weight throughout their first year of life, confirming, on the one hand, their greater vulnerability to diseases, especially diarrhea, and on the other, their growth programmed prenatally. $15,21,22$ When anthropometric indices are adjusted for birth weight, no other significant alteration to weight or stature takes place during the first year of life, denoting the magnitude of the influence of birth weight on future growth patterns. ${ }^{15}$

Absence of maternal breastfeeding or early weaning is a decisive risk factor for malnutrition, 23 but, in this study there was no association between the two variables. A similar case-control study undertaken by Saleemi et al. in order to detect risk factors for stunting at 6, 12, 24 and
60 months, using a cohort of newborn infants, found an identical result. ${ }^{16}$ Curiously, the authors observed that the absence of maternal breastfeeding exhibited a significant association with stunting at the 6-month evaluation, but at 12 months it was LBW and stunting at 6 months that were the most important risk factors, emphasizing the varying determinants of malnutrition at different ages. ${ }^{16}$ In contrast, maternal breastfeeding lasting longer than 6 months was associated with improved linear growth, without a significant relation with weight gain, or presenting less intense association with weight. 24,25 When children are exclusively breastfed during the first months of life and adequate complementary feeding is assured thereafter, physical growth deficits that take place during the first year of life are probably attributable to prenatal factors, represented by LBW. ${ }^{15}$

The influence of socioeconomic and environmental conditions on physical growth has been widely studied and in incontrovertible. Owning a refrigerator is an important factor for preventing food contamination and 
reduces the chances of diarrhea. ${ }^{7}$ The presence of running water and sanitation in the home is an indirect indicator of hygiene and general care, since they forestall the occurrence or repeat infections. ${ }^{25}$ The observation in this sample that not having a toilet presents a three times greater risk of nutritional risk has also been made by other authors. 25 Since the health benefits resulting from access to running water only become apparent once sanitation is improved, and they are therefore complementary variables, it is understandable that just one of them will be significant in the multivariate analysis, as has been observed in other studies. 25,26

It has been questioned whether dysentery is a primary determining factor of physical growth alterations in developing countries, more than anything because the deficits that occur after diarrhea episodes are transitory and, therefore, no longer evident when analyzed at longer intervals. ${ }^{27,28}$ Indeed, some authors have failed to find evidence of a significant effect on long-term growth when the general level of dysentery is tackled, despite reductions in the duration of diarrhea episodes resulting from oral rehydration therapy. ${ }^{27}$ There is no doubt that reducing the incidence and prevalence of diarrhea is a measure of fundamental importance to children's global health, but it is clear that healthcare policies directed exclusively to this end are not enough to optimize physical growth. 27

Nutritional status is the result of the interaction between food consumption and retention and utilization of energy and nutrients, since nutritional abnormalities are caused by one or more of these factors in combination. ${ }^{29}$ Therefore, if a nutritional problem identified by anthropometric indices is not the result of nutrient losses secondary to diarrhea, inadequate consumption or utilization of nutrients must be considered. However, studies of the determinant factors of failure to thrive do not usually include an assessment of nutritional intake. In a study by Checkley et al., a history of diarrhea explained $16 \%$ of stature deficit at 24 months, but there was no association with the duration of diarrhea episodes, raising the possibility that the majority of cases of failure to thrive are not secondary to nutrient losses. ${ }^{26}$ It should be pointed out that inadequate sanitation is a source of gastrointestinal infection, which in turn may be asymptomatic, i.e. it may cause chronic bacterial colonization without diarrhea (environmental enteropathy), interfering with nutrient uptake and growth. ${ }^{26}$ Measuring infections solely by reported episodes or duration of diarrhea, as is habitual in studies, limits the estimate of the biological impact of infection on physical growth, and is a sign that research must continue into the factors that determine growth problems, adjusting and adding pertinent variables to be measured. 30

Low birth weight children are at a disadvantage in terms of physical growth and are also more vulnerable to infections when compared with normal birth weight children. 2,15,21,22 It is possible to speculate that environmental enteropathy is also compromising the utilization of nutrients in these children, contributing to the association between LBW and physical growth deficit.
Nutritional problems and morbidity due to infectious diseases among the children in developing countries still constitute a public health challenge. Identifying the risk factors associated with these events enables the adoption of adequate preventative and curative measures. The results of this study justify specific interventions that should be made to improve birth weight in an attempt to reduce future nutritional problems and physical growth deficits, but the control of adverse environmental factors, such as preventing infections, is also an important measure to optimize the health and nutrition of these children.

\section{References}

1. Barker DJ, Gluckman PD, Godfrey KM, Harding JE, Owens JA, Robinson JS. Fetal nutrition and cardiovascular disease in adult life. Lancet. 1993;341:938-41.

2. Victora CG, Barros CF, Vaughan JP, Teixeira AM. Birthweight and infant mortality: a longitudinal study of 5,914 Brazilian children. Intern J Epidemiol. 1987;16:239-45.

3. World Health Organization. The incidence of low birth weight: a critical review of available information. World Health Stat Q. 1980;33:197-244.

4. Kramer MS. Determinants of low birth weight: methodological assessment and meta-analysis. Bull World Health Organ. 1987;65:663-737.

5. Olinto MT, Victora CG, Barros FC, Tomasi E. Determinants of malnutrition in a low-income population: hierarchical analytical model. Cad Saude Publ. 1993;9 (Supl 1):S14-27.

6. Gigante DP, Victora CG, Araújo CLP, Barros FC. Tendências no perfil nutricional das crianças nascidas em 1993 em Pelotas, Rio Grande do Sul, Brasil: análises longitudinais. Cad Saude Publ. 2003;19 (Supl. 1):S141-7.

7. Lima MC, Motta ME, Santos EC, Silva GA. Determinants of impaired growth among hospitalized children - a case-control study. Sao Paulo Med J. 2004;122:117-23.

8. Martorell R, Khan LK, Hughes ML, Grummer-Strawn LM. Obesity in Latin American women and children. J Nutr. 1998; 128:1464-73.

9. Ministério da Saúde - Pesquisa Nacional sobre Demografia e Saúde/BEMFAM/ Sistema de Informação em Saúde;1996.

10. Rissin A. Estado nutricional de crianças menores de cinco anos: uma análise epidemiológica no Brasil e, especialmente no Nordeste, como uma referência para a fundamentação de programas de intervenção nutricional [dissertação]. Recife (PE): Instituto Materno Infantil de Pernambuco; 1997.

11. Marques NM, Lira PC, Lima MC, Silva NL, Batista Filho M, Huttly $\mathrm{Sr}$, et al. Breastfeeding and early weaning practices in Northeast Brazil: a longitudinal study. Pediatrics. 2001;108:e66. Disponível em: http://www.pediatrics.org.

12. Brasil. Ministério da Saúde. Secretaria de Política de Saúde. Organização Pan Americana da Saúde. Guia alimentar para crianças menores de dois anos. Brasília: Ministério da Saúde; 2002. 152 p.

13. World Health Organization. Measuring change in nutritional status. Geneva; WHO; 1983. 101 p.

14. World Health Organization. Physical status: the use and interpretation of anthropometry. Tech Rep Ser 854; Geneva: WHO; 1995.

15. Dewey KG. Cross-cultural patterns of growth and nutritional status of breast-fed infants. Am J Clin Nutr. 1998;67:10-7.

16. Saleemi MA, Ashraf RN, Mellander L, Zaman S. Determinants of stunting at $6,12,24$, and 60 months and postnatal linear growth in Pakistani children. Acta Paediatr. 2001;90:1304-8.

17. Maleta K, Virtanen S, Espo M, Kulmala T, Ashorn P. Timing of growth faltering in rural Malawi. Arch Dis Child. 2003;88:574-8.

18. de Onis M, Blössner M. The World Health Organization Global database on child growth and malnutrition: methodology and applications. Int J Epidemiol. 2003;32:518-26.

19. Mei Z, Grummer-Strawn LM, Thompson D, Dietz WH. Shifts in percentiles of growth during early childhood: analysis of longitudinal data from the California child health and development study. Pediatrics. 2004;113:e617-27. 
20. de Onis M, Blossner M, Villar J. Levels and patterns of intrauterine growth retardation in developing countries. Eur J Clin Nutr. 1998;52 (Suppl 1):S5-15

21. Arifeen SE, Black RE, Caulfield LE, Antelman G, Baqui AH, Nahar $\mathrm{Q}$, et al. Infant growth patterns in the slums of Dhaka in relation to birth weight, intrauterine growth retardation, and prematurity. Am J Clin Nutr. 2000;72:1010-7.

22. Mamabolo RL, Alberts M, Mbenyane GX, Steyn NP, Nthangeni NG, Delemarre-Van De Waal HA, et al. Feeding practices and growth of infants from birth to 12 months in the central region of the Limpopo Province of South Africa. Nutrition. 2004;20: 327-33.

23. Iqbal Hossain M, Yasmin R, Kabir I. Nutritional and immunisations status, weaning practices and socio-economics conditions of under five children in three villages of Blangadesh. Indian J Public Health. 1999;43:37-41.

24. Simondon KB, Simondon $F$, Costes $R$, Delaunay V, Diallo A. Breast-feeding is associated with improved growth in length, but not weight, in rural Senegalese toddlers. Am J Clin Nutr. 2001;73:959-67.

25. Onyango AW, Esrey SA, Kramer MS. Continued breastfeeding and child growth in the second year of life: a prospective cohort study in western Kenya. Lancet. 1999;354:2041-5.

26. Checkley W, Gilman RH, Black RE, Epstein LD, Cabrera L, Sterling $C R$, et al. Effect of water and sanitation on childhood health in a poor Peruvian peri-urban community. Lancet. 2004;363:112-18.
27. Poskitt EM, Cole TJ, Whitehead RG. Less diarrhea but no change in growth: 15 years' data from three Gambian villages. Arch Dis Child. 1999;80:115-19.

28. Wierbza TF, El-Yazeed RA, Savarino SJ, Mourad AS, Rao M, Baddour $M$, et al. The interrelationship of malnutrition and diarrhea in a periurban area outside Alexandria, Egypt. J Pediatr Gastroenterol Nutr. 2001;32:189-96.

29. Weaver LT. Commentary - Less diarrhea but no change in growth: 15 years' data from three Gambian villages. Arch Dis Child. 1999;80:119-20.

30. Lunn PG, Northrup-Clewes CA, Bownes RM. Intestinal permeability mucosal injury, and growth faltering in Gambian infants. Lancet. 1991;338:907-10.

Correspondence:

Maria Eugênia Farias Almeida Motta Rua Amaraji, 80/1001, Casa Forte CEP 52060-440 - Recife, PE, Brazil Tel.: +55 813269.6807

E-mail: eugenia.motta@uol.com.br 